\title{
聚合物基表面微结构的逐面式制造技术研究进展
}

\author{
汪延成 $^{1,2}$ 刘佳薇 ${ }^{2}$ 盘何旻 ${ }^{2}$ 梅德庆 $^{1,2}$ \\ (1. 浙江大学流体动力与机电系统国家重点实验室 杭州 310027; \\ 2. 浙江大学浙江省先进制造技术重点实验室 杭州 310027)
}

\begin{abstract}
摘要: 聚合物基表面微结构在软体机器人、柔性电子器件、仿生机械、生物医学、组织工程等领域有着广泛的应用, 将逐面 式制造技术应用于聚合物基表面微结构的制造过程可解决传统微压印、光刻、逐点和逐线式制造方法加工周期长、效率低、 大面积表面微结构制造脱模难等问题。发展聚合物基表面微结构的逐面式制造技术是当前先进制造技术的研究热点之一, 具 有广阔的应用前景。首先在阐述了常见的聚合物基表面微结构设计及其制造材料的基础上, 重点论述了光刻、纳米压印、数 字光投影式 3D 打印、能场辅助制造、自组装制造等五类逐面式成形制造技术方面的最新研究进展, 包括各种制造技术的制 造原理、工艺特点及表面微结构的典型应用等。最后, 总结预测了聚合物基表面微结构设计、制造及应用方面的发展趋势, 并对聚合物基表面微结构的逐面式成形制造技术的未来发展进行了展望。
\end{abstract}

关键词: 表面微结构; 逐面式; 投影式 3D 打印; 能场辅助制造; 自组装技术

中图分类号: TH162

\section{Recent Progress on Manufacturing Technologies in Layer-by-layer Mode for the Fabrication of Polymer-based Surface Microstructures}

\author{
WANG Yancheng ${ }^{1,2}$ LIU Jiawei ${ }^{2}$ PAN Hemin ${ }^{2}$ MEI Deqing ${ }^{1,2}$
}

(1. State Key Laboratory of Fluid Power \& Mechatronic Systems, Zhejiang University, Hangzhou 310027;

2. Key Laboratory of Advanced Manufacturing Technology of Zhejiang Province, Zhejiang University, Hangzhou 310027)

\begin{abstract}
Polymer-based surface microstructures have been widely utilized in soft robotic, flexible electronics, bionic machinery, biomedical, tissue engineering and other fields. The applications of layer-by-layer manufacturing technologies to fabricate polymer-based surface microstructures can solve the problems of traditional micro-imprinting, lithography, point-by-point and line-by-line mode manufacturing processes, such as long processing cycles, low efficiency, and difficulty in demolding large-surfaced microstructures. The development of the manufacturing methods in layer-by-layer mode for polymer-based microstructures becomes the hot topic of advanced manufacturing technology. Firstly, the commonly used polymer-based surface microstructures and their manufacturing materials are presented. Then, the recent progress of lithography, nano-imprinting, digital light processing based 3D printing, energy field-assisted manufacturing, self-assembly technologies are studied, including the manufacturing principle, fabrication process and their typical applications. Finally, the development trends of polymer-based surface microstructure design, fabrication, and applications are summarized and forecasted, and future development trends of polymer-based surface microstructures manufacturing technologies are concluded.
\end{abstract}

Key words: surface microstructure; layer-by-layer; projection 3D printing; energy field-assisted manufacturing; self-assembly technology

\section{0 前言}

自然界中的天然材料因其表面特有的微结构形

\footnotetext{
* 国家自然科学基金(52075484, 52175522)和浙江省自然科学基金杰出 青年基金(R19E050001)资助项目。20210420 收到初稿, 20210818 收 到修改稿
}

貌，往往具有比人工材料更优异的性能，如荷叶表 面的微/纳复合乳突结构使其表面具有超疏水性 能 ${ }^{[1]}$ 、蝴蝶翅膀表面的变色特性 ${ }^{[2]}$ 等。随着仿生学研 究不断揭示自然界中表面微结构与其功能特性间的 内在作用机制, 功能性表面微结构的仿生学设计与 制造技术也得到了国内外研究者的关注。当前, 表 
面微结构制造所常用的材料有金属、硅、石英、聚 合物等。其中, 聚对苯二甲酸乙二酯(Polyethylene terephthalate, PET) 、聚二甲基硅氧烷 (Polydimethylsiloxane, PDMS)、聚甲基丙烯酸甲酯 (Polymeric methyl methacrylate, PMMA)等聚合物材 料, 通常具有机械强度高、耐磨性好、生物相容性 好的优点, 在软体机器人、柔性电子器件、仿生机 械、生物医学、组织工程等领域已有诸多研究进展。 比如在柔性电子器件中, 图案化微结构的柔性祄底、 圆柱和金字塔形的微结构阵列等 ${ }^{[3]}$, 已被用作柔性 触觉传感器的敏感结构层, 可提高传感器的检测灵 敏度和响应速率。

随着聚合物基表面微结构应用潜力的不断发 掘和科学技术的进步, 现已发展出多种聚合物基 表面微结构的制造方法及工艺, 如微纳米压印、 金刚石车削、光刻/化学刻蚀、物理气相沉积、激 光加工或表面涂层等, 可直接在聚合物基底上制 造出表面微结构, 使其具有超疏水性、良好摩擦 润滑性能、特殊的光学性质等。单点金刚石切削 与激光加工等制造方法通常采用逐点或逐线式制 造方式, 在表面微结构制造时加工效率低、精度 提升困难, 难以满足聚合物基表面微结构的大面 积精密制造需求。

逐面式成形制造, 可通过一次成形快速制造 出大面积的表面微结构, 可有效克服逐点或逐线 式加工方法的局限, 并显著提高表面微结构的加 工效率。逐面式成形制造方法主要有光刻、纳米 压印 ${ }^{[4]}$ 、数字光投影式 $3 \mathrm{D}$ 打印 ${ }^{[5]}$ 、能场辅助制造、 自组装制造技术 ${ }^{[6]}$ 等。其中, 光刻、纳米压印、 数字光投影式 $3 \mathrm{D}$ 打印可直接在聚合物基底上制 造表面微结构; 能场辅助制造和自组装制造技术 则通过对聚合物基复合材料内的功能介质进行位 置调控和逐面式成形来制造聚合物基功能表面微 结构。因此, 聚合物基表面微结构的逐面式成形 制造技术已成为光学器件、柔性电子、组织工程、 生物医学等领域的研究热点。

本文重点介绍了聚合物基表面微结构逐面式 成形制造技术方面的最新研究进展, 涵盖了目前 常见的聚合物基表面微结构设计及其制造材料、 五类主要表面微结构逐面式成形制造技术及其工 艺以及制造的表面微结构的典型应用等。随后, 总结了当前聚合物基表面微结构逐面式成形制造 技术存在的若干问题和面临的技术挑战, 并对聚 合物表面微结构逐面式成形制造技术的发展趋势 进行了展望。

\section{1 常见的聚合物基表面微结构}

为实现特定功能, 通常需要开展表面微结构设 计, 并研究不同材料基底上表面微结构的制备方法 及工艺。表 1 所示为常见的聚合物基表面微结构及 其制备材料。表面微结构主要有微凸台阵列 ${ }^{[7]}$ 、微 沟槽阵列 ${ }^{[8]}$ 、仿生表面微结构 ${ }^{[9]}$ 等。根据表面微结构 的特性不同，采用的聚合物材料主要有高密度聚乙 烯(High density polyethylene, HDPE)、聚二甲基硅氧 烷、聚乳酸(Polylactic acid, PLA)、聚氯乙烯 (Polyvinyl chloride, PVC) 、聚四氟乙烯 (Polytetrafluoroethylene, PTFE)、高温硫化硅橡胶 (High temperature vulcanized silicone rubber, HTV-SR)、氟化乙丙烯 (Fluorinated ethylene propylene, FEP)、超疏水聚丙烯(Polypropylene, PP)、 光敏树脂(聚酯、聚氨酯和环氧树脂)等 ${ }^{[10]}$ 。

\section{1 聚合物基微凸台阵列}

微凸台阵列结构主要用于超疏水表面、自清洁 表面、射流减阻、非润湿液体转移和微流道等。具 有超疏水性能( 接触角 $>150^{\circ}$, 滑动角 $<10^{\circ}$ ) 的聚 合物基表面应同时满足物理(表面粗粘度)和化学(表 面上的非极性基团)条件。因此，需选择合适的聚合 物材料使得制造的凸台阵列具有微/纳尺度形貌，材 料的表面自由能应显著低于金属基材料。此外，聚 合物基微凸台阵列还应具有良好的机械加工性能。

表面微凸台阵列按照其单元几何结构可分为微 柱阵列、微雉阵列和微金字塔阵列等, 其可在柔性 聚合物(如柔性聚氨酯-丙烯酸酯)基底上采用分层逐 面成形工艺来进行制造。如东芬兰大学的 PAKKANEN 等 ${ }^{[11]}$ 使用具有微柱阵列的铝模先通过 紫外光固化逐面成形, 然后对固化的 PMMA 结构层 进行脱模的制备方法, 来制造表面凸起的微柱阵列。 该方法制备出来的表面微柱单元高 $57 \mu \mathrm{m}$, 长径比 高达 1000 , 具有良好的超疏水性能。清华大学的钟 敏霖等 ${ }^{[12]}$ 采用飞秒激光在不锈钢表面制备出微雉 阵列模板, 并配合热纳米压印工艺制备了 PDMS 微 雉阵列。阵列中的微雉单元高约 $78 \mu \mathrm{m}$, 宽度约为 $50 \mu \mathrm{m}$, 该结构具有超疏水、高透明、热稳定等性能, 可用作微流控芯片中的微流体通道。

微金字塔阵列具有微米级的雉体单元, 且其 独有的多尺度结构可降低表面自由能。韩国汉阳 大学的 SO 等 ${ }^{[13]}$ 采用三维打印工艺制备了一种 PLA 基的微金字塔阵列结构, 其微金字塔单元的 层厚可控制在数十微米, 阵列底面积为 $10 \mathrm{~mm} \times$ 
$10 \mathrm{~mm}$, 可用于微流控器件、太阳能电池、光电 探测器和压力传感器的柔性基底。南京航空航天 大学的 GE 等 ${ }^{[14]}$ 使用 FDM 打印配合化学刻蚀方 法, 实现了在碳基和硅基聚合物上制造微金字塔 阵列, 微金字塔单元的高度和宽度均为 $1 \mu \mathrm{m}$, 并 分析比较了碳基和硅基太阳能电池在微金字塔和 倒置纳米锥体结构下的抗反射性能, 为大电能输
出的 C-Si 太阳能电池的制备提供了可行途径。山 东师范大学的 ZHANG 等 ${ }^{[15]}$ 采用熔融沉积打印配 合碱性刻蚀法在 PDMS 基底上制备了微金字塔形 阵列, 微金字塔单元的大小为 $1.5 \mu \mathrm{m} \times 1.5 \mu \mathrm{m} \times$ $1 \mu \mathrm{m}$, 因此, 该阵列具有良好的超疏水性能, 可 分离液滴与空气, 有望在复杂环境下化学染料分 子的原位检测中得到应用。

表 1 常见的聚合物基表面微结构的种类及材料

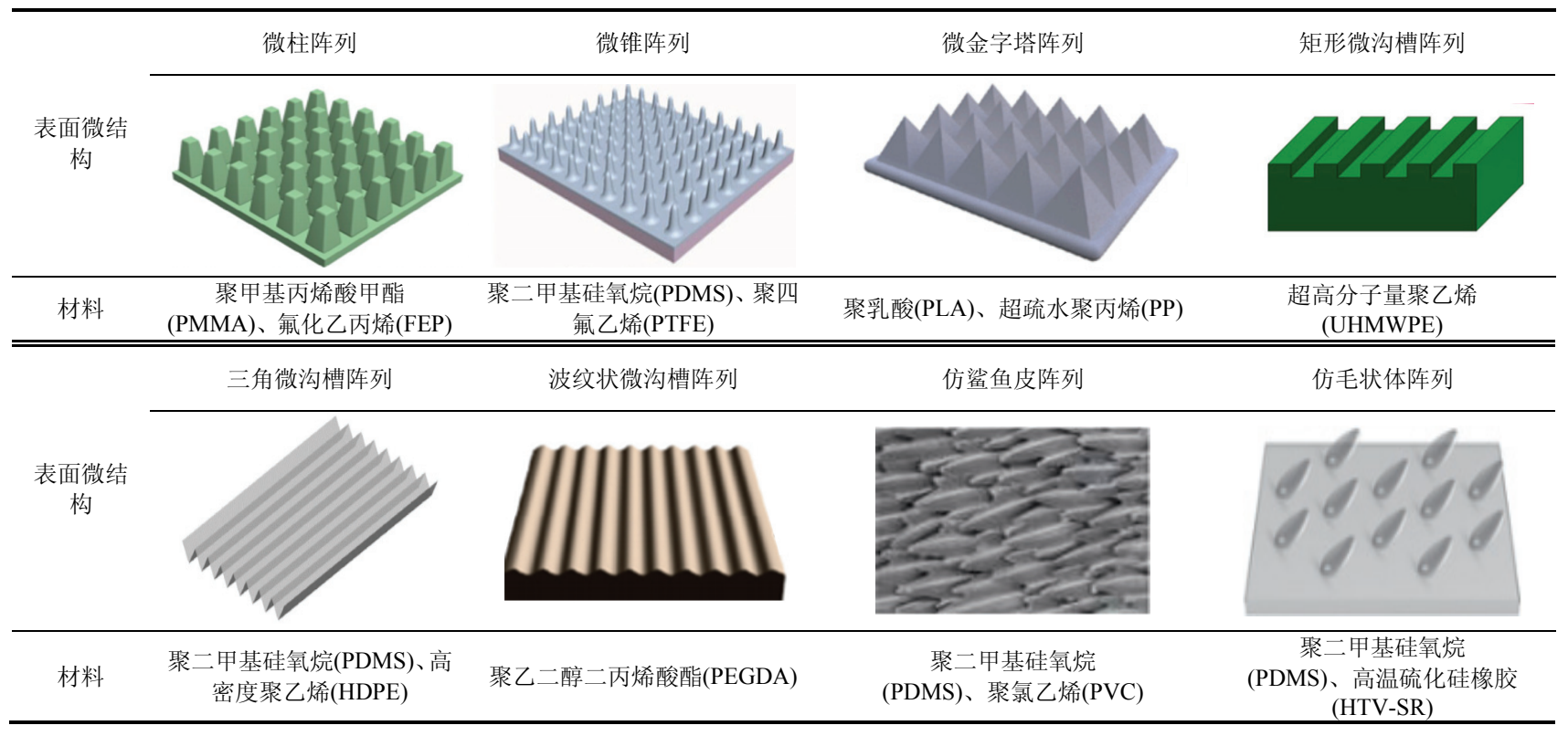

\section{2 聚合物基微沟槽阵列}

微沟槽阵列结构根据其几何结构可分为矩形、 三角形和波纹状微沟槽阵列, 并且因其独特的液体 形状控制和输运特性, 可用于自清洁、油水分离、 减阻、液滴运动控制及微流控芯片中。

光刻和化学刻蚀是在玻璃或硅基底上制造微沟 槽阵列的主要方法。聚合物基微沟槽阵列可通过光 刻、化学刻蚀、物理/化学气相沉积、微纳米压印和 能场辅助制造等方式来进行 ${ }^{[16]}$ 。上海交通大学的 GAO 等 ${ }^{[17]}$ 采用性能优良但成形性较差的超高分子 量聚乙烯粉末, 对其进行微粉热压成形并制备了宽 径比为 8 的矩形微沟槽阵列结构, 结果表明微粉热 压成形工艺制造高精度的微沟槽阵列的可行性。在 微观尺度, 韩国蔚山大学的 LEE 等 ${ }^{[18]}$ 提出了一种利 用超精密加工的金属模具进行纳米压印的方法, 在 热塑性聚合物表面上制备了具有超疏水性能的三角 形微沟槽结构, 沟槽的深度分别为 $10 \mu \mathrm{m} 、 20 \mu \mathrm{m}$ 、 $30 \mu \mathrm{m}$, 实验结果表明该微沟槽阵列微结构具有超疏 水性能, 可用于液体形状控制和输运。

聚合物基微沟槽阵列结构也可采用化学气相沉 积制造方法来进行制备。西班牙巴塞罗那自治大学
的 LIU 等 ${ }^{[19]}$ 采用等离子体增强化学气相沉积技术将 二氧化硅层和非晶硅层沉积在聚合物表面上, 制造 了一种带有交叉矩形微沟槽和生理电极的分区微流 控芯片, 沟槽宽度仅 $20 \mu \mathrm{m}$, 可用于模拟血视网膜 屏障。美国纽约州立大学的 WANG 等 ${ }^{[20]}$ 通过皮秒 激光加工方法直接在聚合物表面上制造了矩形微沟 槽阵列, 该方法可快速制备具有复杂微尺度图案和 可控纳米特征的聚合物表面微结构。

波纹状微沟槽阵列是指表面具有过渡边界曲率 变化平缓的周期性微米级沟和脊结构的微阵列。波 纹状微沟槽阵列可采用声场辅助的光固化 3D 打印 技术来进行制造。浙江大学的 MEI 等 ${ }^{[21]}$ 提出了一种 声场辅助的 3D 打印工艺, 利用一维声表面驻波 (Standing surface acoustic wave, SSAW)在 PEGDA 聚 合物材料上制造波纹状的表面微沟槽结构; 在二维 声表面驻波激励下，可制造出周期性分布的点阵网 状微沟槽阵列。该制造方法采用声表面驻波和光固 化相结合实现周期性表面微结构的快速成形制造, 并且实现了微波纹阵列幅度在 $3 \sim 10 \mu \mathrm{m}$ 范围的准 确控制。与传统技术相比, 该制造方法不需要实体 模具设计就可实现光滑的表面微结构制造, 可应用 
于柔性电子和生物医学等领域。

\section{3 聚合物基仿生微结构阵列}

自然界中的生物体多具有值得人类借鉴优异性 能的表面微结构。采用机械设计、材料科学等多学 科交叉手段来仿生模拟生物结构, 并研究仿生结构 的形貌、性质、功能等特性。聚合物基仿生微结构 阵列具有仿生生物结构的特性, 在超疏水表面、高 强度结构、组织工程等领域有着较广泛应用。

聚合物基仿生微结构阵列可采用辊涂、压印、 化学刻蚀、能场辅助光固化等逐面成形工艺来进行 制备。韩国崇实大学的 PARK 等 ${ }^{[22]}$ 在 PDMS 中加入 质量分数为 $10 \%$ 的碳纳米管, 采用基于非牛顿流体 不稳定性开发的辊式涂布工艺, 制造了具有超疏水 功能的䰇毛状的仿鲨鱼皮结构。该结构阵列的平均 高度为 $30 \sim 40 \mu \mathrm{m}$, 宽度为 $17.4 \mu \mathrm{m}$, 与实际鲨鱼皮 结构表面尺寸接近, 不仅具有耐久性和自清洁能力, 还可增强液体流过表面时的减阻效果。中国科学院 上海硅酸盐研究所的 $\mathrm{TANG}$ 等 ${ }^{[23]}$ 采用天然夹竹桃叶 片作为物理气相沉积模板, 在 PDMS 薄膜表面制备 了仿生叶片微结构薄膜, 在此基础上制作了压阻式 柔性压力传感器。仿生叶片微结构的引入有利于柔 性电极的变形, 引起接触电阻值变化, 还会影响导 电层的裂纹和聚结行为, 为柔性传感器的结构设计 提供了新思路。

用于制备仿生微结构阵列的能场辅助光固化
3D 打印技术也成为超疏水表面以及高强度高韧 性结构表面的一种新兴制备工艺。为研究微结构 几何形状对表面润湿性的影响, 台湾清华大学的 HUANG 等 ${ }^{[24]}$ 采用铁磁流体成形法制备了不同倾 角的微纳米尺度 PDMS 锥体阵列, 研究表明微雉 单元倾角在 $50^{\circ}$ 时所制备的仿生阵列在疏水和保 水之间达到了相对平衡，可应用于超疏水表面的 结构优化设计研究。生物壳体结构具有低密度、 高强度和高韧性等特点, 美国南加州大学的 YANG 等 ${ }^{[25]}$ 提出了一种电场辅助光固化 $3 \mathrm{D}$ 打印 技术，仿生美洲海螯虾钳制备多壁碳纳米管各向 异性排列的增强结构, 来提高所制备仿生微结构 的力学性能; 利用高纵横比碳纳米管的各向异性, 进一步提高仿生微结构的多功能性。该方法同样 可用于模拟人体半月板纤维排列, 以制备强化的 人工半月板复制品。

\section{2 表面微结构的制造工艺及方法}

聚合物基表面微结构的逐面式制造方法主要有 光刻、纳米压印光刻、数字光投影式 $3 \mathrm{D}$ 打印、能 场辅助制造、自组装制造技术, 本文将详细阐述这 五类制造方法的工艺原理和制造特点, 并在表 2 中 对比了五类制造技术的材料、特征尺寸、加工微结 构及制造装备等技术特点。

表 2 五类可逐面式制造表面微结构的制造技术特点对比

\begin{tabular}{|c|c|c|c|c|c|}
\hline & 光刻技术 & 纳米压印技术 & $\begin{array}{l}\text { 数字光投影式 3D } \\
\text { 打印技术 }\end{array}$ & 能场辅助制造技术 & 自组装制造技术 \\
\hline 材料 & 硅、氧化硅 & 硅、氧化硅、聚合物 & 光敏树脂 & $\begin{array}{l}\text { 功能介质的 } \\
\text { 光敏树脂 }\end{array}$ & 高分子材料、纳米材料 \\
\hline 特征尺寸 & 亚微米级 & 纳米级 & 微米级 & 微米级 & 纳米级 \\
\hline 加工微结构 & $\begin{array}{c}\text { 图案化微纳结构制造, 用 } \\
\text { 于传感器、光栅等器件 }\end{array}$ & $\begin{array}{c}\text { 简单微纳图案的 } \\
\text { 批量制造 }\end{array}$ & $\begin{array}{l}\text { 复杂微结构的 } \\
\text { 个性化制造 }\end{array}$ & $\begin{array}{c}\text { 功能性微结构 } \\
\text { 的制造 }\end{array}$ & $\begin{array}{c}\text { 特定结构与功能的微纳 } \\
\text { 结构自组装制造 }\end{array}$ \\
\hline 制造装备 & 光刻机 & 压印机 & $\begin{array}{c}\text { 数字光投影式 } \\
\text { 3D 打印机 }\end{array}$ & $\begin{array}{c}\text { 磁辅助/声辅助 } \\
\text { 3D 打印机 }\end{array}$ & 无特定设备 \\
\hline
\end{tabular}

\section{1 光刻技术}

光刻是一种图形复印和化学腐蚀相结合的精密 表面加工技术, 是制备微电子、光电器件的关键工 艺。在光刻过程中, 光源的能量穿过掩模版的通透 区域并通过投射系统到覆盖有光刻胶的基底材料表 面, 通过曝光的方式使材料发生改变, 并通过后续 处理, 在基底材料上形成和掩模版一致的微纳结构。 光刻胶分为正胶和负胶, 正胶材料曝光之后能够通 过显影溶液快速溶解, 而未曝光部分不会被溶解, 负胶则恰恰相反。

在光刻过程中, 光子可激发电子-空穴对从而导
致材料的腐蚀。溶液低 $\mathrm{pH}$ 值和高电压能够加速导 电层的腐蚀过程, 其中电场是影响腐蚀效果的最重 要因素。西北工业大学的段利兵等 ${ }^{[26]}$ 提出了一种不 需要底部导电层就可制备任意微结构的光刻半导体 材料的方法, 解决了传统光刻工艺制造纳米微结构 时导电层在氧化锌薄膜下使氧化锌短路的问题。该 方法直接在玻璃基板上沉积了 $\mathrm{ZnO}$ 薄膜, 微结构可 以在数秒内制备, 精度可达数十微米, 所制备的 $\mathrm{ZnO}$ 微电极可用于微流控芯片的止血效果评估。

\section{2 纳米压印技术}

纳米压印(Nanoimprint lithography, NIL)是在压 
力、温度或紫外光辅助作用下, 将预先设计的模板 上的图案转印到涂覆在基底上的压印胶上, 再通过 干法或湿法刻蚀、去胶等工艺将图案转移到目标衬

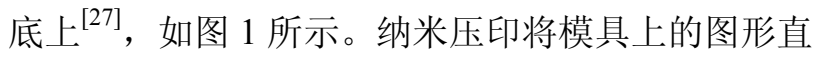
接转移到祄底上, 从而达到量产化的目的, 具有加 工原理简单、分辨率高、生产效率高、成本低等优 点。根据辅助方式的不同可分为热纳米压印、紫外 光纳米压印和其他纳米压印技术。

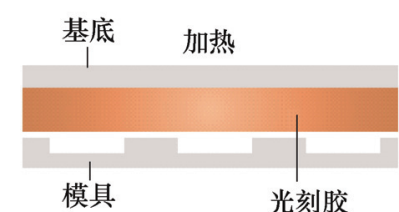

(a) 加热

脱模

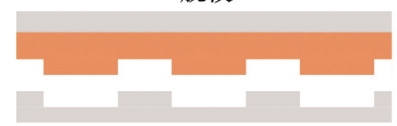

(c) 脱模

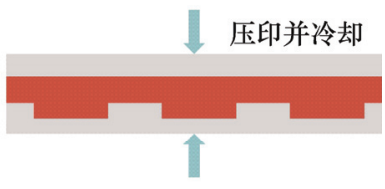

(b) 压印并冷却

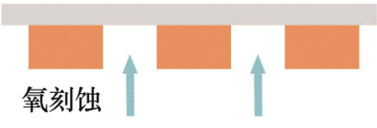

(d) 氧刻蚛
图 1 纳米压印过程示意图

热纳米压印是通过加热使压印胶薄膜达到玻 璃态温度以上使其具有流动性, 并在压力作用下 填满模板凹槽, 然后降温到抗蚀剂玻璃态转化温 度以下进行固化, 经过脱模工艺后, 祄底上会形 成与模板图案相吻合的微结构 ${ }^{[28]}$ 。德国凯泽斯劳 滕大学的 NOWDURI 等 ${ }^{[29]}$ 利用热纳米压印与金电 镀技术在金蒸发表面制备了仿牛跟腱 I 型胶原纤 维的类胶原金纳米结构, 结构宽度介于 $200 \mathrm{~nm} \sim$ $5 \mu \mathrm{m}$ 、高约 $35 \mathrm{~nm}$ 。在该结构上培养小鼠肠内神 经元细胞, 可促进神经元细胞及网络在纳米结构 表面的生长与扩散。热纳米压印通常需要经历加 热、缓慢冷却等耗时久的过程, 因此微结构的制 造效率偏低。

基于紫外光固化的纳米压印技术，采用可紫外 光固化的光敏树脂代替压印胶填充模板空隙, 用紫 外光照射固化后可得到图案化的树脂结构。中国科 学技术大学的王亮等 ${ }^{[30]}$ 提出了一种紫外光固化的 双面纳米压印金属转印方法, 用于制作柔性电容式 触觉传感器, 该传感器的电极阵列相互重叠, 由金 刚石铝网组成, 实现了 $94 \%$ 的透过率和各向异性的 表面电阻率。

\section{3 数字光投影式 3D 打印技术}

3D 打印在个性化设计的表面微结构制造中 具有高度灵活性和简易性。其中, 基于数字光处 理(Digital light processing, DLP)的投影式 3D 打印 技术是以光敏树脂为打印材料, 通过将数字掩模

调制后的紫外光照射在光敏树脂表面使其发生光 固化得到特定结构, 从而实现复杂结构的逐面式 打印制造。相较于传统的逐点、逐线式打印, 数 字光投影式 3D 打印工艺具有精度高、速度快的 优点。图 2 所示为数字光投影式 3D 打印装置及 制造的跨尺度树枝状支架和毛细血管网状支架结 构 $^{[31]}$ 。

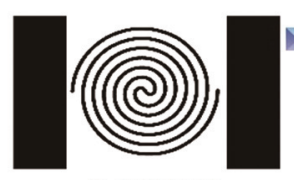

数字掩模版

$365 \mathrm{~nm}$ 紫外光

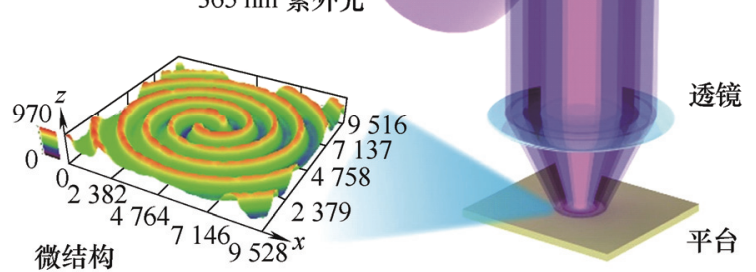

(a) 数字光投影式 $3 \mathrm{D}$ 打印系统原理图

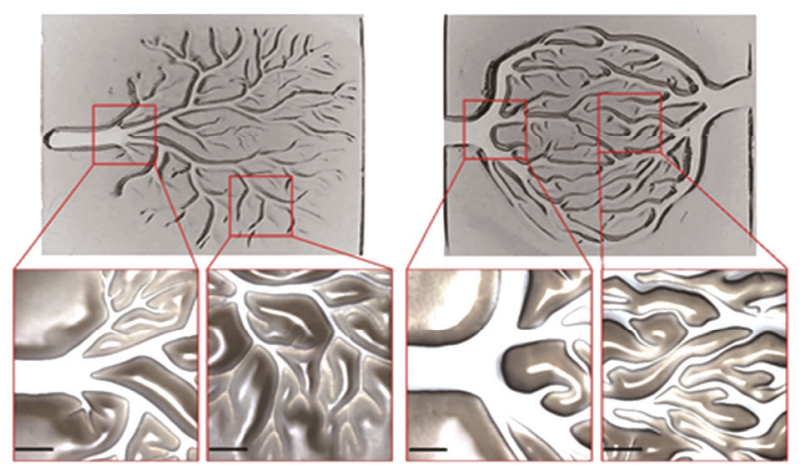

(b) 树枝状支架和毛细血管网状支架的整体和细节的光学图像

图 2 数字光投影式 $3 \mathrm{D}$ 打印技术 ${ }^{[31]}$

数字光投影式 $3 \mathrm{D}$ 打印技术的本质是由离散像 素形成连续二维图案, 多层叠加进而形成三维立 体结构, 这导致了采用这种技术打印制备的微结 构表面粗糙度较高。新加坡科技设计大学的 YUAN 等 ${ }^{[32]}$ 提出了一种振动辅助 DLP 打印方法来 制造微透镜阵列, 机械振动可消除离散像素形成 的锯齿状表面，实现具有光滑表面的光学元件的 精密制造, 并通过 1 3 s 单灰度紫外光曝光来消 除阶梯效应。该方法能制造出各种形状的微透镜, 为高质量、快速、灵活性强的光学元件制造提供 了有效手段。数字光投影式 3D 打印技术同样具有 对复杂表面微结构的曲面制造能力。西安交通大 学的 ZHANG 等 ${ }^{[33]}$ 采用数字光投影式 $3 \mathrm{D}$ 打印技 术，基于氮化嗍纳米管/光敏树脂复合材料，直接 
在球形模具上打印制备了具有曲面微结构的高灵 敏度压电共形传感器, 能够有效贴合机器人手指 尖, 实现了机器人手的触觉感知和不均匀表面力 的空间分布检测。

中国科学院的高文等 ${ }^{[34]}$ 利用 DMD 无掩模曝 光技术, 采用拼接加工的方法实现了大面积微结 构的快速制造, 大面积微结构的加工需要将单个 百微米级尺寸的微结构作为子场单元, 每次曝光 仅曝光单个子场单元, 将多个子场单元有序排布 拼接成具有大面积的微结构, 就可制备出毫米级 的微结构, 且加工精度高。浙江大学的 WANG 等 ${ }^{[35]}$ 采用拼接制造的方法, 通过数字光投影式 $3 \mathrm{D}$ 打印技术实现了高精度跨尺度的仿生毛细血管微 结构的制造。

\section{4 能场辅助制造技术}

数字光投影式 $3 \mathrm{D}$ 打印技术可实现对表面微结 构的逐面投影式快速成形制造, 为增强聚合物基表 面微结构的电、磁、光学及机械性能, 常在聚合物 基体中加入不同物理/化学性质的材料作为功能介 质, 以满足构件在微电子、化学和生物医学等领域 的应用需求。

电/磁场可以调控导电或磁性粒子在聚合物 基体中的分布位置及取向, 并通过数字光投影式 $3 \mathrm{D}$ 打印技术将光敏树脂固化, 得到具有特殊物理 化学性质的表面微结构。美国南加州大学的 YANG 等 ${ }^{[36]}$ 采用电场辅助的 $3 \mathrm{D}$ 打印技术来制造 了具有复杂三维结构的仿贝壳结构, 如图 $3 \mathrm{a}$ 所 示。该方法利用电场诱导光敏聚合物基质中的石 墨烯纳米片排列组装, 再通过数字光投影式 3D 打印技术制备具有复杂几何形状的复合结构。该 结构具有与天然贝壳层相当的韧性和强度, 还具 有导电各向异性。吉林大学的周雪莉等 ${ }^{[37]}$ 提出了 一种磁场辅助 3D 打印制造钢纤维定向排布复合 材料的方法, 并对所制备材料的力学性能进行了 表征。美国伊利诺伊大学的 JOYEE 等 ${ }^{[38]}$ 提出了 一种新型的多尺度多材料磁场辅助 $3 \mathrm{D}$ 打印方法 (Magnetic field-assisted stereolithography, M-SL), 用于打印表面特征从纳米到毫米甚至厘米级的颗 粒-聚合物结构, 并设计和打印了一种受生物启发 具有微米尺度的雉形结构、纳米尺度的孔和表面 皱纹的层次结构, 该结构使聚合物表面性质由亲 水性变为疏水性。此外, 层次化的表面结构也为 细胞的附着和生长创造了更好的环境, 细胞接种 后 $72 \mathrm{~h}$ 的活细胞数量比非结构化光滑表面的活细
胞数量多 $900 \%$ 。

电/磁场辅助排布要求功能介质自身具有导 电或磁特性, 而对于陶瓷、高分子聚合物等其他 功能介质, 上述排布方法不再适用; 且电/磁场辅 助排布只能实现如条纹、向心或离心形式的排布, 无法实现对功能介质进行区域化选择性的排布与 调控。声表面波辅助微颗粒排布, 对微颗粒的形 状及物理性质没有特定要求, 故可实现对聚合物 基质中的任意类型微颗粒进行移动和排布。声表 面波辅助微颗粒排布通过形成稳定的空间超声能 场, 使悬浮其中的微颗粒受到声辐射力的作用向 势阱处运动并最终保持稳定。浙江大学的 HAN 等 ${ }^{[39]}$ 提出了一种基于声表面波和紫外光固化相 结合的聚合物基表面微结构的声模微成形工艺, 通过实验研究了声表面波能场与表面微结构特征 形貌间的对应关系; 并通过波导微结构设计, 实 现了局域化微结构的选区成形制造, 如图 $3 \mathrm{~b}$ 所 示。以色列巴伊兰大学的 SAZAN 等 ${ }^{[40]}$ 提出了一 种利用声表面驻波在预定位置沉积持续聚合反应 的产物(如 PDMS), 以实现原位制备表面微结构 的方法。

\section{5 自组装制造技术}

自组装制造技术是利用分子或原子之间的微 弱作用力, 使其通过类似于结晶的方式自发形成 所需要的表面微结构的技术。自组装已成为一种 高效的自下而上的制造技术，可实现对原本随机 取向的分子精确控制, 使之成为高度有序的聚集 体。随着分子堆积复杂性的增加, 分子组装体往 往具有独特的性质。典型的自组装制造技术包括 水热/溶剂热法、热蒸发法、模板法、外场辅助 法等。

但自组装制造技术的可控性略差, 难以按 照设计的需求对自组装区域进行调控。因此常 将光刻、纳米压印等与自组装制造技术相结合, 制造出高精度微结构。中国香港理工大学的黄 维扬等 ${ }^{[41]}$ 将高通量纳米压印技术与金属多吡啶 体系的自组装技术相结合, 制备出规则排列的纳 米棒, 并通过改变纳米压印图案来控制成形的结 构, 如图 4 所示。美国亚利桑那州立大学的 SONG 课题组 ${ }^{[42]}$ 开发了一种基于 3D 打印的纳米颗粒层 选择性沉积和排列放置技术, 采用合理的沉积密 度和纳米颗粒的优先排列, 研制了一款高性能的 化学传感器, 可检测低浓度的气态和液态挥发性 有机化合物。 

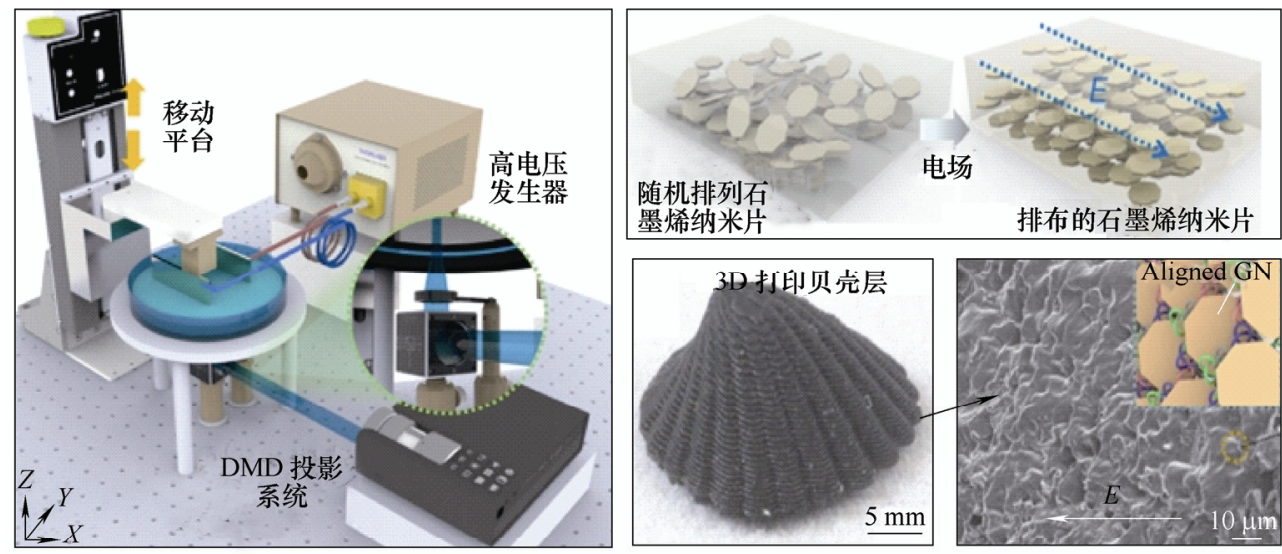

(a) 电场辅助光固化 3D 打印装置示意图及制造的贝壳结构实物图 ${ }^{[36]}$
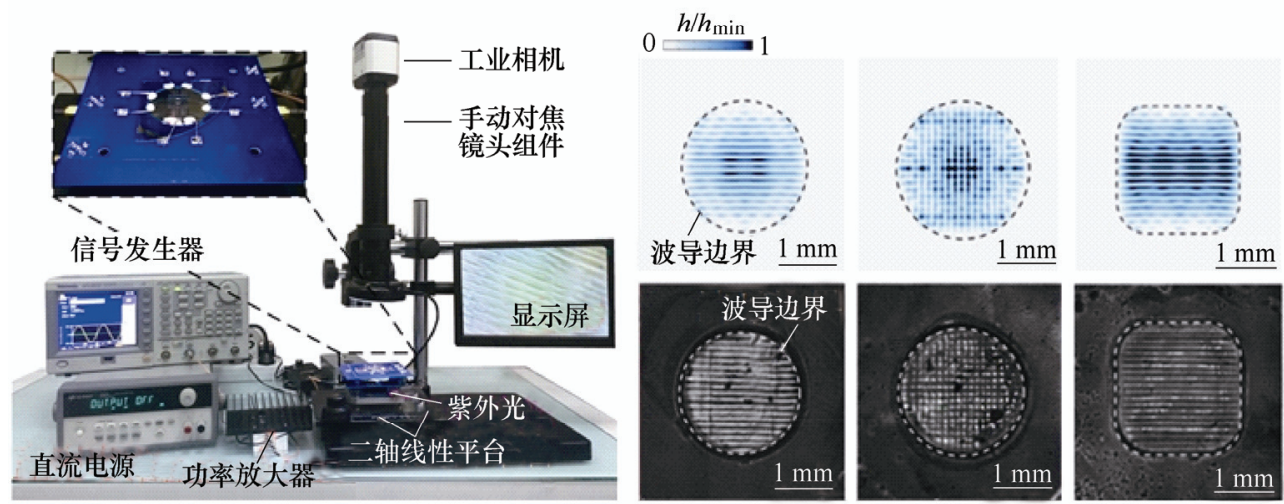

(b) 声场辅助光固化3D打印装置示意图及制造的波纹状微沟槽结构实物图 ${ }^{[39]}$

图 3 能场辅助制造技术

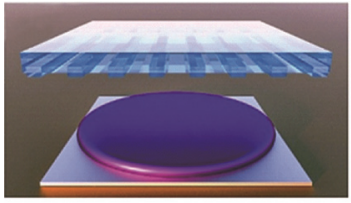

落模铸造 FePt 材料

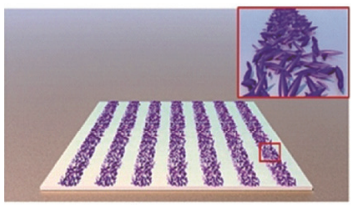

图案化纳米棒

(a) 自组装工艺过程

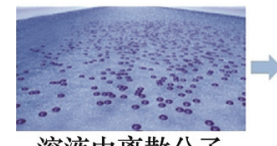

溶液中离散分子

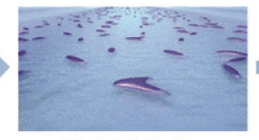

纳米棒生长

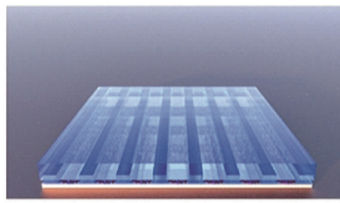

图案印刷和沿特征方向的原位 自组装

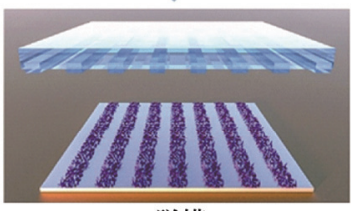

脱模 (b) 纳米棒在模具型腔内形成 ${ }^{[41]}$

图 4 自组装工艺过程及纳米棒在模具型腔内形成过程

3 聚合物基表面微结构的典型应用

聚合物基表面微结构因具有良好的生物相容性
和易与功能材料复合的特点, 在生物医学和微电子 领域有着广泛的应用前景 ${ }^{[43]}$ 。此外，聚合物基表面 微结构还具备制造复合压电材料和介电层所需的电 学特性、光学器件所需的光学特性 ${ }^{[44]}$ 。

\section{1 表面微结构在光学领域的应用}

传统光学元件增透的方法是在光学元件表面 镀一层或多层增透膜, 以达到光学增透的目的, 然而由于传统增透膜制备会导致热失配、稳定性 差等问题，使得该方法存在一定的局限。采用逐 面成形工艺在光学元件表面制造微结构以实现增 透的效果, 可有效提升稳定性。日本三菱化工科 技创新中心的 UOZU 等 ${ }^{[45]}$ 对光学表面加工圆雉形 表面微结构阵列, 以制备仿蛾眼型抗反射膜来实 现增透效果，如图 5a 所示。该结构具有优良的机 械性能, 不受物理化学性质等因素的影响。与传 统增透膜相比, 仿蛾眼型抗反射薄膜在整个可见 光波长内的反射率较低。美国麻省理工学院的 PARK 等 ${ }^{[46]}$ 使用纳米压印技术来制备具有雉形纳 米微结构的高透光度光学表面, 如图 $5 \mathrm{~b}$ 所示。通 过聚合物表面细长的雉形阵列使有效折射率与绝 热折射率匹配以降低反射率，这种纳米微结构表 
面还具有较强的防雾和自清洁功能, 为光伏太阳 能电池等应用提供了可能。中国台湾大学的 YANG 等 ${ }^{[47]}$ 采用固定边界热纳米压印技术制作了 具有高精度双面 V 形槽结构的高亮度塑料导光 板, 如图 5c 所示。该技术制备的表面微沟槽结构 的厚度均匀性较好, 制造的高亮度导光板尺寸偏 差小, 达到了光学应用的要求。

聚合物基表面微结构的制造精度极大地影响光 学元件的性能。中国台湾高雄应用科学大学的 WU
等 ${ }^{[48]}$ 采用封闭的模具与模具镶块压印加热的 PMMA 祄底来制造具有 V 形槽结构的塑料导光板。 闭式热模压能提供较好的表面微结构制造精度, 由 于成形应力等引起的光学各向异性也可明显降低。 中国台湾清华大学的 LIU 等 ${ }^{[49]}$ 在双辊加工中配合紫 外光逐面成形工艺制造了用于显示的亚波长光栅, 如图 5d 所示。并基于严格耦合波分析研究了当光线 通过带有背光图案的亚波长光栅时, 不同形状光栅 的一阶透射/反射效率与光栅柾距的关系。

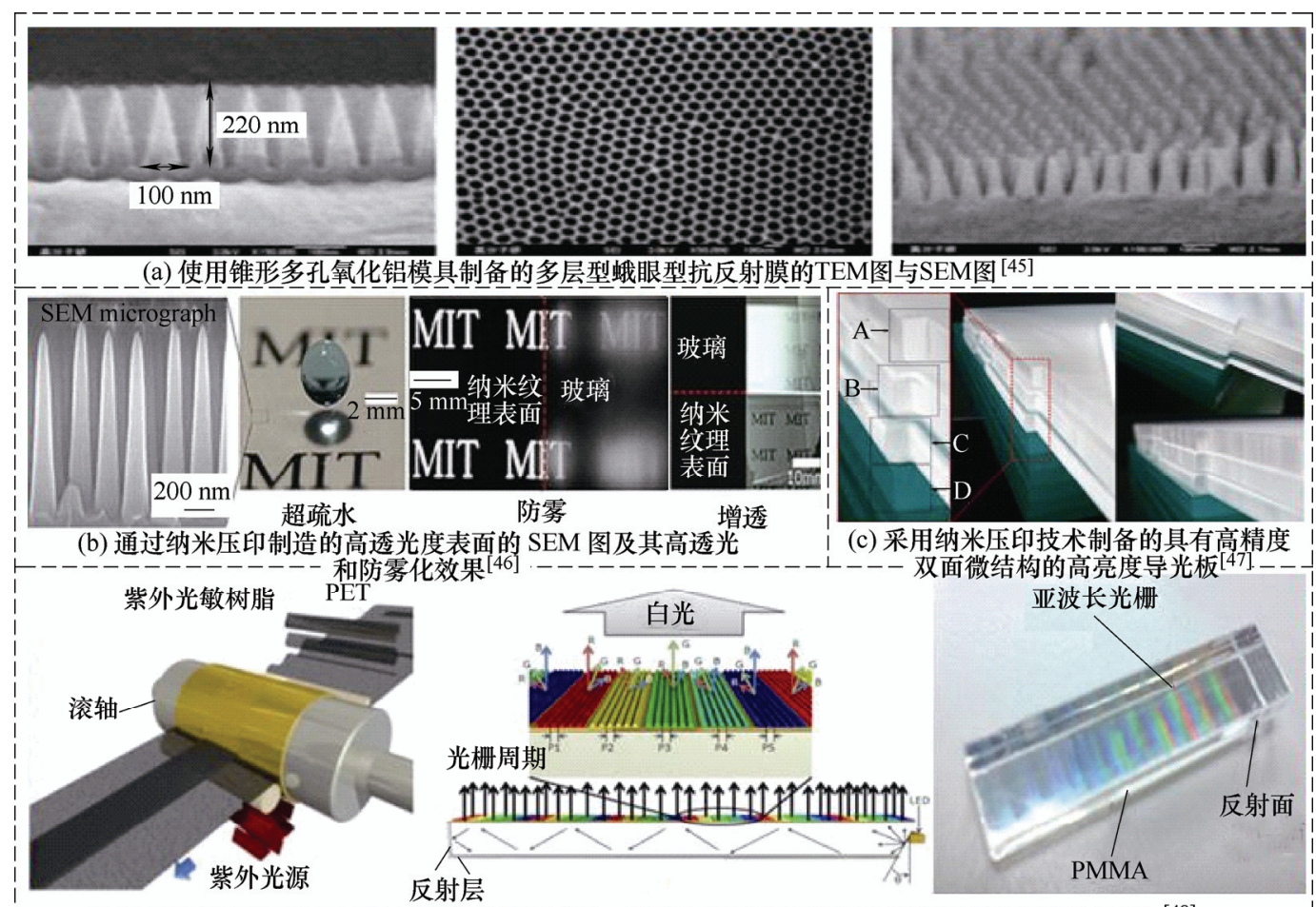

(d) 制备白光波导表面的 UV 压花设备结构示意、白光波导表面功能实现原理及白光波导表面实物 ${ }^{[48]}$

图 5 表面微结构在柔性电子领域的典型应用

\section{2 表面微结构在柔性电子领域的应用}

随着信息终端逐步从大型主机向可穿戴设备推 进, 电子器件有向柔性化发展的趋势。柔性电子技 术的研究热点在于新型电子材料和器件的研发, 如 模拟皮肤多功能性的电子皮肤 ${ }^{[50]}$ 。柔性触觉传感器 能够响应外界刺激, 对智能机器人、医疗健康、移 动设备等领域的智能化发展起到重要的推动作用。 研究人员通过探索不同的触觉传感原理, 研制了电 容式、电阻式、压电式、摩擦电式等触觉传感器 ${ }^{[51]}$, 并不断提高传感器的触觉检测性能。

在电容式柔性触觉传感器的介电层中引入聚合 物基表面微结构能有效提升传感器的力检测灵敏 度、并增大触觉力的量程范围 ${ }^{[52]}$ 。哈尔滨工业大学 的胡平安课题组 ${ }^{[33]}$ 以微金字塔结构作为介电层, 提 出了一种高灵敏度的三轴柔性触觉传感器结构, 如 图 6a 所示。通过在 PDMS 微金字塔阵列上逐层组
装还原氧化石墨烯(Reduced graphene oxide, rGO), 制造了一款 $3 \times 3$ 的阵列传感器, 结合离子型电容器 的高灵敏特性, 提高了传感器的灵敏度。韩国国立 蔚山科学技术研究所的 $\mathrm{KO}$ 课题组 ${ }^{[54]}$ 采用纳米压印 技术制备具有多层互锁微球阵列结构的柔性电子皮 肤, 如图 $6 \mathrm{~b}$ 所示。柔性介电层的表面微球阵列用于 多层互锁以提高电子皮肤的压力检测灵敏度, 并且 这种逐面成形工艺可制作柔性铁电传感器, 在较宽 的压力范围内具有高灵敏度和响应性。

采用聚合物基微结构制备工艺来进行柔性触觉 传感器的制备, 通常具有快速、简单、低成本、高 精度等优点, 现已广泛应用于高精度柔性触觉传感 器的制备过程中。中科院的汪正平课题组 ${ }^{[50]}$ 以等离 子体刻蚀自组装的聚苯乙烯微球单层阵列为初始模 板，采用简单、低成本的两步复制技术制备具有表 面均匀圆顶状微结构的高性能柔性压阻式压力传感 
器。该柔性压力传感器具有高灵敏度和超低检测极 限, 快速响应时间为 $100 \mathrm{~ms}$ 。美国斯坦福大学的鲍 哲南课题组 ${ }^{[55]}$ 通过纳米压印技术制备了三角形微 沟槽阵列结构, 并研制了一种基于接触电阻机制的 新型电阻式压力传感器, 解决了电阻式压力传感器 在体积压阻效应下工作的常见问题, 实现了触觉压 力的高灵敏度、低阈值、低滞后、优良的可循环性 和温度检测稳定性。

聚合物基表面微结构在软体机器人领域也有广 泛的应用。相较于传统气动或液压驱动, 形状记忆 聚合物和水凝胶对外部刺激(如温度、酸碱度和电场) 做出响应的软体机器人, 具有致动快、体型小、易 于控制等优点。电活性水凝胶(Electroactive hydrogel, $\mathrm{EAH}$ )在电场作用下具有较大的变形能力, 作为一种 潜在的软体机器人和人工肌肉驱动材料已受到广泛 关注。美国罗格斯大学的 HAN 课题组 ${ }^{[56]}$ 提出了通 过三维设计和数字光投影式 3D 打印技术精确控制 软体机器人尺寸和微结构的方法, 实现了 $\mathrm{EAH}$ 的复 杂三维驱动, 并通过实验演示了软体机器人抓取、 运输物体以及多向驱动。

\section{3 表面微结构在组织工程领域的应用}

组织工程可在体外获取不同类型组织的结构和
功能 ${ }^{[57]}$ 。然而, 大多数方法在制备对组织功能至关 重要的复杂结构的能力上有局限, 如脉管或心脏腔 等组织具有复杂曲面和中空腔, 其准确制备较为困 难 ${ }^{[58]}$ 。

采用毛细力光刻制备图案化细胞板这一逐面成 形工艺, 可严格控制单个细胞层的厚度, 从而制备 致密、无支架的仿生组织。美国华盛顿大学的 KIM 课题组 ${ }^{[59]}$ 采用毛细力光刻逐面成形工艺制备了热 响应的纳米图案化细胞基底, 如图 $6 \mathrm{c}$ 所示, 其表面 具有的矩形微沟槽阵列可用于细胞支架的放置。通 过添加不同的细胞类型、模具形状和水凝胶, 可以 制备更复杂的三维结构, 并实现特定组织的定制生 长。采用该方法制成的人体组织缩放模型, 可用于 研究组织的结构与功能间的关系及发育成熟过程。 葡萄牙民和大学的 CLARISSE RIBEIRO 课题组 ${ }^{[60]}$ 采用光刻法制备了表面具有线形和六边形排列的矩 形微沟槽的聚偏氟乙烯-三氟乙烯(Poly(vinylidene fluoride- trifluoroethylene), P(VDF-TrFE))支架, 并 通过检测前成骨细胞的增殖和分化, 来研究 P(VDF-TrFE) 电活性微支架对骨细胞增殖和分化的 影响。结果表明各向异性表面微结构不需要进一步 的生化刺激就能促进骨分化。

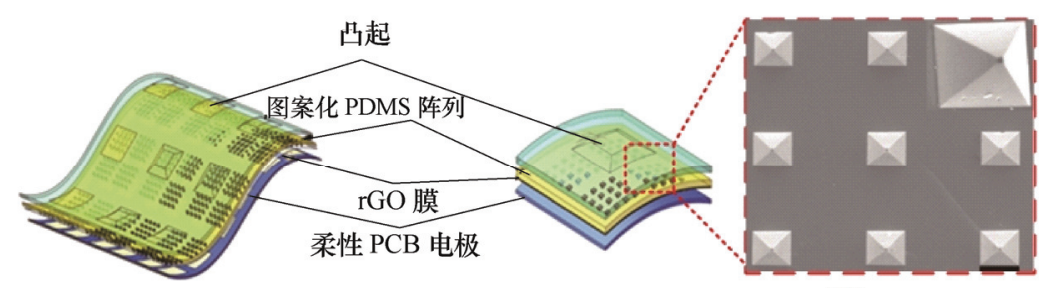

(a) 柔性触觉传感器中的图案化 PDMS 衬底及表面微金字塔阵列 ${ }^{[53]}$

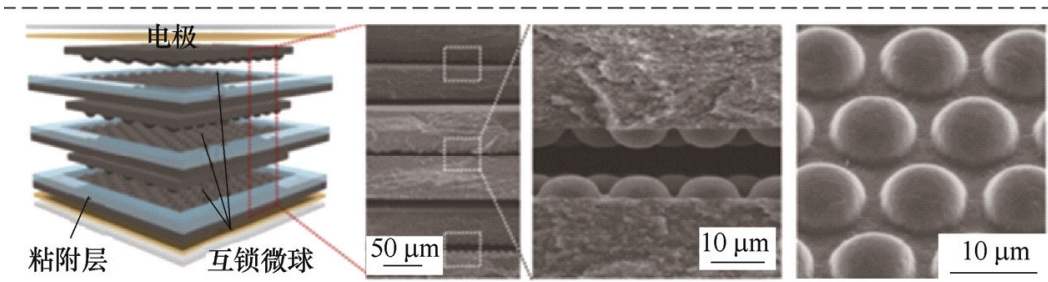

(b) 多层互锁微球的柔性电子皮肤结构示意及表面微球阵列的 SEM 图 ${ }^{[54]}$

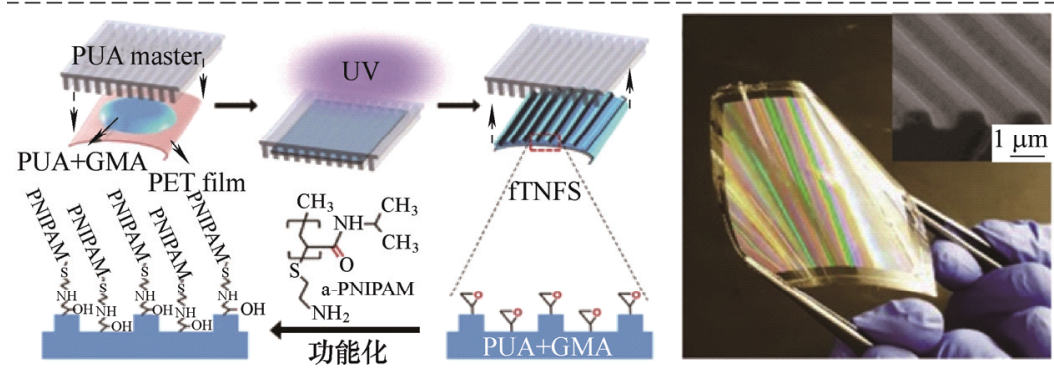

(c) 使用毛细管力光刻技术和胺端热响应功能化技术制造的柔性纳米图案化基底 流程示意和制造的具有表面微沟槽阵列的纳米结构板实物 [59]

图 6 表面微结构在组织工程领域的典型应用

为使制备的仿生支架具有良好的生物力学特性 和细胞植入活性, 复杂结构图案的仿生细胞支架还 
可采用 3D 打印工艺来进行制备。英国德蒙福特大 学的 MUSA 课题组 ${ }^{[61]}$ 使用 3D 打印技术制备了表面 具有复杂微结构的聚醚醚酮复合材料成骨细胞支 架。与传统制备技术相比, 这种制备工艺能更好地 控制生物活性相的分布且具有更好的生物相容性和 生物力学性能。伊朗沙希德 - 贝赫什蒂医科大学的 ARASH 课题组 ${ }^{[62]}$ 通过 $3 \mathrm{D}$ 打印技术制备了含有聚 $(D, L)$-丙交酯和 $\beta$-磷酸三钙的复合支架, 作为间充 质干细胞成骨分化的平台。制备的骨支架表面具有 精确可控的孔径和孔隙率, 并且具有较高的机械强 度、优良的生物相容性和成骨分化能力, 为 $3 \mathrm{D}$ 打 印纳米复合材料制备表面微结构用于个性化骨组织 工程展现了广阔的应用前景。

\section{4 聚合物基表面微结构制造技术的发 展趋势}

随着新材料和新制造工艺的不断发展, 聚合物 基表面微结构的制造精度得到了显著提高, 制备的 表面微结构的性能也在不断提升。若要使聚合物基 表面微结构在生物医学、柔性电子等领域得到进一 步应用, 还需要在逐面式成形制造工艺及表面微结 构设计两方面不断改进。

\section{1 逐面式成形制造技术}

表面微结构的逐面式成形制造技术已不再局限 于单一材料或结构的制造, 往往需要在复合材料中 实现功能介质的规律性排布和整体结构成形制造。 前述聚合物基表面微结构的制造中, 光刻、纳米压 印和数字光投影式 $3 \mathrm{D}$ 打印等技术主要用于整体表 面微结构的成形, 能场辅助和自组装制造技术则用 于对功能粒子进行排布, 将两类以上制造技术进行 结合, 从而实现复合材料基体的表面微结构制造。

目前使用的能场辅助制造聚合物表面微结构工 艺大多是单一能场辅助, 但如前所述, 电场或磁场 只能排布导电或磁性粒子, 声场辅助对粒子性质无 特殊要求但排布的图案形貌较为有限。想要实现更 加复杂的表面微结构制造往往需要利用两种以上的 复合能场, 通过对不同能场分布区域、时序的调控 以获得预期的制造结构。如利用声场辅助调节功能 介质分布位置的同时利用电场或磁场改变其取向, 得到空间各向异性的表面微结构, 进一步扩展功能 及应用。北京航空航天大学的蔡军等 ${ }^{[63]}$ 提出了一种 利用流场流动剪切和电场静电相互作用在大范围内 排列各种导电微/纳米粒子的方法。该方法对包括镀 银玻璃球、碳纳米管和石墨烯在内的导电微纳米粒
子组装具有通用性, 为基于有序导电微纳米粒子的 功能复合材料的大规模制备提供了条件。

\section{2 可变形状的聚合物基表面微结构}

前述制造的这些单一微结构通常表现出恒定的 各向同性或各向异性特殊性能。通过将微结构制造 技术与形状记忆聚合物等材料相结合, 可获得形状 可变的聚合物基表面微结构。

聚合物的可控性归因于其优异的形状记忆效 应, 使其表面具有记忆不同微观结构形状和润湿性 能的能力。哈尔滨工业大学的成中军等 ${ }^{[64]}$ 通过模拟 荷叶和水稻叶上的微结构, 在形状记忆聚合物上制 备了一种能够在超疏水各向同性的莲叶型和超疏水 各向异性的水稻叶型之间可逆传递的表面结构。通 过制造可变形的聚合物基表面微结构, 可对表面光 学特性进行调节。新加坡科技设计大学的 ZHANG 等 ${ }^{[65]}$ 利用双光子聚合光刻技术制造大小可调的多 种颜色网格组成的结构, 随着纳米结构变平缓, 结 构表面颜色变得不可见, 并在超过其玻璃化转变温 度的几秒钟内就能恢复纳米结构的原始表面形貌及 其结构颜色。

\section{3 分层多尺度的聚合物基表面微结构}

具有微纳米分层结构的聚合物表面具有优异 的机械性能、光学性能、化学性能等优点。微米和 纳米结构相结合形成分层多尺度微结构, 不仅具有 更稳定的性能, 而且比单尺度微结构的纵横比更 低, 不易受制造条件的限制。中南大学的周明勇课 题组 ${ }^{[66]}$ 提出了一种采用阳极氧化铝模板与蚀刻板 相结合的方法来制造高纵横比纳米管和微纳米表 面复合结构的新方法, 制备了带有表面微米柱和纳 米柱阵列的模具嵌件, 有效提高了分层表面微结构 的最终制造质量。哈尔滨工业大学的成中军课题 组 ${ }^{[67]}$ 通过在形状记忆聚合物上制备微/纳米层次结 构阵列, 得到了一种具有形状记忆能力的超疏水表 面, 可以改变和恢复其层次结构及润湿性。通过设 计与微结构相关的图案, 成功地将该表面应用于可 重写的液滴存储功能芯片中, 突破了目前结构图案 无法重新编程的瓶颈。

\section{5 结论与展望}

聚合物基表面微结构在生物医学、组织工程、 柔性电子器件、仿生机械、软体机器人等领域有着 广阔的应用前景。随着新材料、新工艺的发展, 制 造的聚合物基表面微结构的复杂精细程度也在不断 提升。逐面式成形制造技术因其成形速度快、精度 
高、可实现复杂结构制造等优点, 在聚合物基表面 微结构的制造中具有明显优势。本文总结了近年来 聚合物基表面微结构制造技术的发展现状, 重点阐 述了聚合物基表面微结构的不同种类及应用, 并对 几种常用的表面微结构逐面式成形制造技术进行了 详细论述。

当前聚合物基表面微结构的逐面式成形制造技 术仍处于发展阶段, 各种逐面式成形制造技术仍面 临着诸多技术难题, 如纳米压印的难点在于高品质 模板的设计与制造 ${ }^{[68]}$, 数字光投影式 $3 \mathrm{D}$ 打印技术 的难点在于可打印材料的种类有限, 无法满足工程 应用的需求。因此，采用逐面式成形制造工艺来制 备聚合物基表面微结构在实际应用中仍面临着以下 挑战。

（1）现阶段逐面式制造技术制造的聚合物基表 面微结构的形式和功能都比较单一, 难以精确复制 天然微结构的形貌及性能。发展通过多种逐面式制 造工艺复合的制造技术来实现更加复杂、更高精度 的表面微结构制备, 成为聚合物基表面微结构逐面 式制造技术发展的最新趋势。

(2) 随着 4D 打印技术的提出和不断发展, 可调 变形的聚合物基表面微结构 4D 打印制造技术成为 新的发展方向, 具有广阔的前景。目前 4D 打印技 术在聚合物基表面微结构制造方面的制备方法及工 艺仍不成熟，适用材料种类少及制造成本高等问题 限制了该技术的大规模应用。

（3）单一的表面微结构性能的提高与其微结构 的形状尺度有着密切关系, 但微结构长宽比增加的 同时也会导致微结构的制造困难、表面耐磨性下降。 因此需要引入分层多尺度微结构, 在提高表面微结 构特殊性能的同时改善其表面耐磨性。

(4) 光刻与纳米压印技术的工程应用需要解决 模板的制造、模板的寿命、压印缺陷控制等技术难 题; 而自组装制造技术由于组装驱动力的控制精度 差、组装单元的多分散性, 组装结构通常还存在长 程无序、组装缺陷难以有效避免等问题, 是实现聚 合物基表面微结构逐面式成形制造技术规模化工程 应用所需要突破的技术瓶颈。

\section{参 考 文 献}

[1] WANG D H, SUN Q Q, HOKKANEN M J, et al. Design of robust superhydrophobic surfaces[J]. Nature, 2020, 582(7810): 55-59.

[2] LLOYD V J, NADEAU N J. The evolution of structural colour in butterflies[J]. Current Opinion in Genetics and Development, 2021, 69: 28-34.
[3] HENSLEIGH R M, CUI H, OAKDALE J S, et al. Additive manufacturing of complex micro-architected graphene aerogels[J]. Materials Horizons, 2018, 5(6): 1035-1041.

[4] PANDEY A, TZADKA S, YEHUDA D, et al. Soft thermal nanoimprint with a $10 \mathrm{~nm}$ feature size[J]. Soft Matter, 2019, 15(13): 2897-2904.

[5] 史玉升, 伍宏志, 间春泽, 等. 4D 打印 - 智能构件的增 材制造技术 $[\mathrm{J}]$. 机械工程学报，2020，56(15): 1-25. SHI Yusheng, WU Hongzhi, YAN Chunze, et al. Four-dimensional printing - the additive manufacturing technology of intelligent components[J]. Journal of Mechanical Engineering, 2020， 56(15): 1-25.

[6] XUN D F, KOHSUKE K, MATTHEW G C, et al. Single crystal texture by directed molecular self-assembly along dual axes[J]. Nature Materials, 2019, 18(11): 1235-1243.

[7] FANG S J, HUSSON S, FU C K, et al. Flexible tactile sensor array utilizing microstructured PDMS bumps with pedot: PSS conductive polymer[C]// IEEE International Conference on Micro Electro Mechanical Systems (MEMS), New York, 2017, pp. 1029-1032.

[8] GUO B, YU X, ZENG Z, et al. Ultra-precision cutting of linear micro-groove array for distributed feedback laser devices[J]. International Journal of Nanomanufacturing, 2018, 14(1): 9-22.

[9] ZHAO X, CHEN L, LI D F, et al. Biomimetic construction peanut-leaf structure on ammonium polyphosphate surface: Improving its compatibility with poly(lactic acid) and flame-retardant efficiency simultaneously[J]. Chemical Engineering Journal, 2021, 412: 128737-10.

[10] YAO Z F, WANG J Y, PEI J. High-performance polymer field-effect transistors: From the perspective of multi-level microstructures $[\mathrm{J}]$. Chemical Science, 2021, 12(4): 1193-1205.

[11] SAARIKOSKI I, JOKI K F, SUVANTO $\mathrm{M}$, et al. Superhydrophobic elastomer surfaces with nanostructured micronails[J]. Surface Science, 2012，606(1-2): 91-98.

[12] GONG D, LONG J, JIANG D, et al. Robust and stable transparent superhydrophobic polydimethylsiloxane films by duplicating via a femtosecond laser-ablated template[J]. ACS Applied Materials \& Interfaces, 2016, 8(27): 17511-8.

[13] KANG B, HYEON J, SO H. Facile microfabrication of 3-dimensional (3D) hydrophobic polymer surfaces using 3D printing technology[J]. Applied Surface Science, 2020, 499: 143733-8.

[14] TANG Q, YAO H, XU B, et al. Integrated effect of hierarchical structure combining isotropic worm-like pit 
with anisotropic inverted nanopyramid for quasi-omnidirectional c-Si solar cell[J]. Materials Science in Semiconductor Processing, 2021, 121: 105363-7.

[15] XU J, SI Y, LI Z, et al. Multiscale structure enabled effective plasmon coupling and molecular enriching for SERS detection[J]. Applied Surface Science, 2021, 544: 148908-10.

[16] ABUBAKER S S, ZHANG Y. Optimization design and fabrication of polymer micro needle by hot embossing method[J]. International Journal of Precision Engineering and Manufacturing, 2019, 20(4): 631-640.

[17] GAO J, PENG L, DENG Y, et al. Experimental studies on micro powder hot embossing for high-aspect-ratio microstructures with ultra-high molecular weight polyethylene powders[J]. Journal of Micromechanics and Microengineering, 2020, 30(11): 115011-10.

[18] LEE K M, NGO C V, JEONG J Y, et al. Fabrication of an anisotropic superhydrophobic polymer surface using compression molding and dip coating[J]. Coatings, 2017, 7(11): 194-12.

[19] LIU H, JIANG W, DING Y, et al. Roller-reversal imprint process for preparation of large-area microstructures[J]. Journal of Vacuum Science \& Technology B , Nanotechnology and Microelectronics : Materials, Processing, Measurement, and Phenomena, 2010, 28(1): 104-109.

[20] WANG Z, NANDYALA D, COLOSQUI C E, et al. Glass surface micromachining with simultaneous nanomaterial deposition by picosecond laser for wettability control[J]. Applied Surface Science, 2021, 546: 149050-9.

[21] MEI D Q, XUE D, WANG Y C, et al. Undulate microarray fabrication on polymer film using standing surface acoustic waves and ultraviolet polymerization[J]. Applied Physics Letters, 2016, 108(24): 241911-4.

[22] PARK S H, LEE S, MOREIRA D, et al. Bioinspired superhydrophobic surfaces, fabricated through simple and scalable roll-to-roll processing[J]. Scientific Reports, 2015, 5: 15430-9.

[23] TANG H, NIE P, WANG R, et al. Piezoresistive electronic skin based on diverse bionic microstructure[J]. Sensors and Actuators A: Physical, 2021, 318: 112532-9.

[24] HUANG C Y, LAI M F, LIU W L, et al. Anisotropic wettability of biomimetic micro/nano dual-scale inclined cones fabricated by ferrofluid-molding method[J]. Advanced Functional Materials, 2015, 25(18): 2670-2676.

[25] YANG Y, CHEN Z, SONG X, et al. Biomimetic anisotropic reinforcement architectures by electrically assisted nanocomposite 3D printing[J]. Advanced Materials, 2017, 29(11): 1605750-20.
[26] DUAN L, LV X, HE Q, et al. Geometry-on-demand fabrication of conductive microstructures by photoetching and application in hemostasis assessment[J]. Biosensors and Bioelectronics, 2020, 150: 111886-6.

[27] 戈欢, 张发军, 黄海瑛, 等. 纳米压印调控 PCL-b-PLLA 受限结晶取向行为的研究 [J]. 高分子学报, 2019, 50(01): 82-90.

GA Huan, ZHANG Fajun, HUANG Haiying, et al. Studies on the crystallization orientation in micromolded PCL-b-PLLA thin films[J]. Acta Polymerica Sinica, 2019, 50(1): 82-90.

[28] 罗怡, 问旭, 陈莉, 等. 聚合物微结构热辅助超声波压 印成形 $[J]$. 光学精密工程, 2014, 22(05): 1220-1226.

LUO Yi, YAN Xu, CHEN Li, et al. Replication of polymer microstructure using thermal-assistedultrasonic embossing[J]. Optics and Precision Engineering, 2014, 22(05): $1220-1226$.

[29] NOWDURI B, SCHULTE S, DECKER D, et al. Biomimetic nanostructures fabricated by nanoimprint lithography for improved cell-coupling[J]. Advanced Functional Materials, 2020, 30(45): 2004227-10.

[30] YANG M, XU K, WANG L. Flexible touch sensor fabricated by double-sided nanoimprint lithography metal transfer[J]. Nanotechnology, 2020, 31(31): 315302-5.

[31] XUE D, WANG Y C, ZHANG J X, et al. Projection-based 3D printing of cell patterning scaffolds with multiscale channels[J]. ACS Applied Materials \& Interfaces, 2018, 10(23): 19428-19435.

[32] YUAN C, KOWSARI K, PANJWANI S, et al. Ultrafast three-dimensional printing of optically smooth microlens arrays by oscillation-assisted digital light processing[J]. ACS Applied Materials \& Interfaces, 2019, 11(43): 40662-40668.

[33] ZHANG J, YE S, LIU H, et al. 3D printed piezoelectric BNNTs nanocomposites with tunable interface and microarchitectures for self-powered conformal sensors[J]. Nano Energy, 2020, 77: 105300-12.

[34] 高文, 郑美玲, 金峰, 等. 飞秒激光快速制备大面积二 维微纳结构 $[\mathrm{J}]$. 激光与光电子学进展, 2020, 57(11): 111421-8.

GAO Wen, ZHENG Meiling, JIN Feng, et al. Fast fabrication of large-area two-dimensional micro/ nanostructure by femtosecond laser[J]. Laser \& Optoelectronics Progress, 2020, 57(11): 111421-8.

[35] WANG Y, WANG Y C, MEI D Q, et al. Scalable printing of bionic multiscale channel networks through digital light processing-based three-dimensional printing process[J]. 3D Printing and Additive Manufacturing, 2020, 7(3): 115-125. 
[36] YANG Y, LI X, CHU M, et al. Electrically assisted 3D printing of nacre-inspired structures with self-sensing capability[J]. Science Advances, 2019, 5(4): 9490-11.

[37] MA Y, WU Q, DUANMU L, et al. Bioinspired composites reinforced with ordered steel fibers produced via a magnetically assisted 3D printing process[J]. Journal of Materials Science, 2020, 55(32): 15510-15522.

[38] JOYEE E B, SZMELTER A, EDDINGTON D, et al. Magnetic field-assisted stereolithography for productions of multimaterial hierarchical surface structures[J]. ACS Applied Materials \& Interfaces, 2020, 12(37) : 42357-42368.

[39] HAN C Y, WANG Y C, MEI D Q. Acoustofluidic waveguides for fabrication of localized polymeric microstructure arrays[J]. Applied Physics A: Materials Science and Processing, 2020, 126(8): 651-12.

[40] SAZAN H, PIPERNO S, LAYANI M, et al. Directed assembly of nanoparticles into continuous microstructures by standing surface acoustic waves[J]. Journal of Colloid and Interface Science, 2019，536: 701-709.

[41] MENG Z, LI G, YIU S C, et al. Nanoimprint lithography-directed self-assembly of bimetallic Iron-M (M=Palladium , Platinum) complexes for magnetic patterning $[\mathrm{J}]$. Angewandte Chemie- International Edition, 2020, 59(28): 11521-11526.

[42] JAMBHULKAR S, XU W, FRANKLIN R, et al. Integrating $3 \mathrm{D}$ printing and self-assembly for layered polymer/nanoparticle microstructures as high-performance sensors[J]. Journal of Materials Chemistry C, 2020, 8(28): 9495-9501.

[43] D'IMPERIO L A, MCCROSSAN A F, NAUGHTON J R, et al. Arrays of electrically-addressable, opticallytransmitting 3D nanostructures on free-standing, flexible polymer films[J]. Flexible and Printed Electronics, 2018, 3(2): $025007-8$.

[44] SONG X, FU D, SHAH S, et al. UV - micropatterned miniaturization : Rapid in situ photopatterning and miniaturization of microscale features on shrinkable thermoplastics[J]. Advanced Materials Technologies, 2020, 5(6): 2000146-7.

[45] UOZU Y, TABOR C E, KAJZAR F, et al. Continuous roll imprinting of moth-eye antireflection surface using anodic porous alumina and multi-functionalities on the moth-eye surface[C]//International Conference on Organic Photonic Materials and Devices XXII, 2020.

[46] PARK K C, CHOI H J, CHANG C H, et al. Nanotextured silica surfaces with robust superhydrophobicity and omnidirectional broadband supertransmissivity[J]. ACS Nano, 2012, 6(5): 3789-3799.
[47] YANG C H, YANG S Y. A high-brightness light guide plate with high precise double-sided microstructures fabricated using the fixed boundary hot embossing technique[J]. Journal of Micromechanics and Microengineering, 2013, 23(3): 035033-14.

[48] WU C H, LU C H. Fabrication of an LCD light guide plate using closed-die hot embossing[J]. Journal of Micromechanics and Microengineering, 2008, 18(3): 035006-10.

[49] LIU C W, LEE C H, LIN S C. Sub-wavelength gratings fabricated on a light bar by roll-to-roll UV embossing process[J]. Optics Express, 2011，19(12): 11299-11311.

[50] WANG L, HUANG X, WANG D, et al. Lotus leaf inspired superhydrophobic rubber composites for temperature stable piezoresistive sensors with ultrahigh compressibility and linear working range[J]. Chemical Engineering Journal, 2021, 405: 127025-10.

[51] GAN X, WANG J, WANG Z, et al. Simultaneous realization of conductive segregation network microstructure and minimal surface porous macrostructure by SLS 3D printing[J]. Materials \& Design, 2019, 178: 107874-10

[52] 汪延成, 鲁映肜, 丁文, 等. 柔性触觉传感器的三维打 印制造技术研究进展 [J]. 机械工程学报, 2020, 56(19): 239-252.

WANG Yancheng, LU Yingtong, DING Wen, et al. Three recent progress on-dimensional printing processes to fabricate flexible tactile sensors[J]. Journal of Mechanical Engineering, 2020, 50(19): 239-252.

[53] ZHANG J, ZHOU L J, ZHANG H M, et al. Highly sensitive flexible three-axis tactile sensors based on the interface contact resistance of microstructured graphene[J]. Nanoscale, 2018, 10(16): 7387-7395.

[54] LEE Y, PARK J, CHO S, et al. Flexible Ferroelectric sensors with ultrahigh pressure sensitivity and linear response over exceptionally broad pressure range $[\mathrm{J}]$. ACS Nano, 2018, 12(4): 4045-4054.

[55] PAN L, CHORTOS A, YU G, et al. An ultra-sensitive resistive pressure sensor based on hollow-sphere microstructure induced elasticity in conducting polymer film[J]. Nature Communications, 2014， 5: 3002-8.

[56] DAEHOON H, CINDY F, CHEN Y, et al. Soft robotic manipulation and locomotion with a 3D printed electroactive hydrogel[J]. Applied Materials \& Interfaces, 2018, 10: 17512-17518.

[57] MOHAMMADI M , MOUSAVI SHAEGH S A , ALIBOLANDI $\mathrm{M}$, et al. Micro and nanotechnologies for bone regeneration: Recent advances and emerging designs[J]. Journal of Controlled Release, 2018, 274: 
35-55.

[58] SUETHAO S, SHAH D U, SMITTHIPONG W. Recent progress in processing functionally graded polymer foams[J]. Materials (Basel), 2020, 13(18): 4060-16.

[59] WILLIAMS N P, RHODEHAMEL M, YAN C, et al. Engineering anisotropic 3D tubular tissues with flexible thermoresponsive nanofabricated substrates[J]. Biomaterials, 2020, 240: 119856-10.

[60] MARQUES-ALMEIDA T, CARDOSO V F, GAMA M, et al. Patterned piezoelectric scaffolds for osteogenic differentiation[J]. International Journal of Molecular Sciences, 2020, 21(21): 8352-8.

[61] OLADAPO B I, ZAHEDI S A, ISMAIL S O, et al. 3D printing of PEEK-cHAp scaffold for medical bone implant[J]. Bio-Design and Manufacturing, 2020, 4(1): 44-59.

[62] REZAI RAD $\mathrm{M}$, FAHIMIPOUR F , DASHTIMOGHADAM E , et al. Osteogenic differentiation of adipose-derived mesenchymal stem cells using 3D-Printed PDLLA/ $\beta$-TCP nanocomposite scaffolds[J]. Bioprinting, 2021, 21: 00117-9.

[63] CAI J, LI X, MA L, et al. Facile large-scale alignment and assembly of conductive micro/nano particles by combining both flow shear and electrostatic interaction[J]. Composites Science and Technology, 2019, 171: 199-205.

[64] CHENG Z, ZHANG D, LV T, et al. Superhydrophobic shape memory polymer arrays with switchable isotropic/anisotropic wetting[J]. Advanced Functional Materials, 2018, 28(7): 1705002-11.

[65] ZHANG W, WANG H, WANG $\mathrm{H}$, et al. Structural multi-colour invisible inks with submicron 4D printing of shape memory polymers[J]. Nature Communications, 2021, 12(1): 112-8.

[66] ZHOU M, XIONG X, JIANG B, et al. Fabrication of high aspect ratio nanopillars and micro/nano combined structures with hydrophobic surface characteristics by injection molding[J]. Applied Surface Science, 2018, 427: 854-860.

[67] LV T, CHENG Z, ZHANG D, et al. Superhydrophobic surface with shape memory micro/nanostructure and its application in rewritable chip for droplet storage[J]. ACS Nano, 2016, 10(10): 9379-9386.

[68] 李延强, 兰红波, 许权, 等. 纳米压印复合软模具建模 研究[J]. 机械工程学报, 2018，54(19): 170-181.

LI Yanqiang, LAN Hongbo, XU Quan, et al. Modeling of flexible composite mold for nanoimprint lithography[J]. Journal of Mechanical Engineering, 2018, 54(19): 170-181.

作者简介: 汪延成(通信作者), 男, 1982 年出生, 博士, 教授。主要研 究方向为机器人智能感知与检测、微制造技术。

E-mail: yanchwang@zju.edu.cn

刘佳薇, 女, 1997 年出生, 硕士研究生。主要研究方向为声表面波辅助 光固化三维打印技术。

E-mail: 21925168@zju.edu.cn

盘何旻, 男, 1998 年出生, 硕士研究生。主要研究方向为声表面波辅助 光固化三维打印技术。

E-mail: 22025069@zju.edu.cn

梅德庆, 男, 1973 年出生, 博士, 教授, 博士研究生导师。主要研究方 向为微细成形、微制造技术、三维打印技术。

E-mail: medqmei@zju.edu.cn 